\title{
Morphological Analysis of Maxillary First Premolars by Cone Beam Computed Tomography in a Chilean sub-population
}

\author{
Análisis Morfológico de Primeros Premolares Maxilares a través de \\ Tomografía Computarizada de haz Cónico en una Subpoblación Chilena
}

Daniela Matus ${ }^{1}$; Ramón Fuentes ${ }^{1,2}$; Pablo Navarro ${ }^{3} \&$ Pablo Betancourt $^{1,2}$

MATUS, D.; FUENTES, R.; NAVARRO, P. \& BETANCOURT, P. Morphological analysis of maxillary first premolars by Cone Beam Computed Tomography in a Chilean sub-population. Int. J. Morphol., 38(5):1266-1270, 2020.

SUMMARY: The root canal system of the maxillary first premolar (MFP), present a high rate of variation, especially at apical level. This complicates the action of antiseptic solutions and endodontic instruments at this level. The object of this in vivo study was to analyse by Cone Beam Computed Tomography (CBCT) the radicular and canalicular morphology of MFP in a Chilean sub-population. We carried out a cross sectional, descriptive and observational in vivo study with CBCT examinations of 70 MFP, both left and right. The data were analysed using descriptive statistics (mean (M), standard deviation (SD), with a confidence interval of $95 \%$ ), and one-factor ANOVA was used to relate the sections observed. Tooth 1.4 presented one root in $64.86 \%$ of cases and two roots in $35.15 \%$. Tooth 2.4 presented one root in $66.67 \%$ of cases and two roots in $33.33 \%$. The frequency of one and two canals was observed to be $30 \%$ and 70 $\%$ respectively. The walls with the smallest cementodentinal thickness were the mesial $(1.11 \pm 0.55)$ and distal (1.08 \pm 0.52$)$. The thickest dentinal wall was the palatine (2.07 \pm 1.29$)$, followed by the buccal (1.6 \pm 1.0$)$. No statistical differences between males and females were found in the thickness of the root wall, nor in the location of the premolar in the maxilla ( $>0.05)$. In conclusion, the root morphology of the MFP is highly variable. Care must be taken not to over-instrument the proximal walls to avoid perforations or fractures. CBCT has proved to be a useful and effective diagnostic tool for in vivo study of dental morphology.

Endodontics.

KEY WORDS: Root canal anatomy; Maxillary first premolar; Vertical root fracture; Cone Beam Computed Tomography;

\section{INTRODUCTION}

Dental morphology is complex and can present multiple variations. For this reason, thorough knowledge of internal root morphology is the basis for successful endodontic treatment. A poor prognosis after therapy generally results from failure to locate a root canal, and from instrumentation which is either incomplete or at an excessive diameter (Abarca et al., 2014).

The root canal system of the maxillary first premolar (MFP), present a high rate of variation, especially at apical level. This complicates the action of antiseptic solutions and endodontic instruments at this level. These variations have been associated with differences in race and geographical location between different populations (Kartal et al., 1988; Pécora et al., 1992; Awawdeh et al., 2008).
The MFP is the tooth which most commonly receives endodontic treatment, with a treatment rate between $15.8 \%$ and $21.5 \%$ of all teeth treated (Wayman et al., 1994). It is considered one of the most difficult teeth to treat ( $\mathrm{Li}$ et al., 2013), due to factors like variations in the number of roots, high incidence of two canals $(73.3 \%$ to $92 \%)$, differing configurations of the pulp cavity, narrow entrance at the furcation and deep mesial concavities (Katz et al., 2006; Awawdeh et al.; Li et al.). Although the MFP habitually presents one or two roots, it has been observed that it may present a third root in $1.7 \%$ of cases (Ahmad et al., 2016).

PradeepKumar et al. (2016) reported that the maxillary teeth that most frequently suffer vertical root fracture (VRF) are the premolars, agreeing with other studies (Cohen et al.,

\footnotetext{
${ }^{1}$ Department of Integral Adult Dentistry, Dental School, Universidad de La Frontera, Temuco, Chile.

${ }^{2}$ Research Center for Dental Sciences (CICO), Endodontic Laboratory, Universidad de La Frontera, Temuco, Chile.

${ }^{3}$ Universidad Autónoma de Chile, Chile.

Sponsored by: DIUFRO Project DI18-0051 - INI 2018.
} 
2006; Awawdeh et al.). VRF is the second most frequent cause of tooth loss after endodontic treatment; it is considered a very serious clinical problem (Sathorn et al., 2005), since once it occurs, treatment is limited to extraction of the tooth or resection of the fractured root (Lertchirakarn et al., 1999).

VRF is defined as a complete or incomplete longitudinal fracture of the root, extending throughout the dentin thickness from the root canal to the periodontal zone (Lertchirakarn et al., 1999). This can generate complications such as: significant bone resorption (PradeepKumar et al.), appearance of a deep, narrow periodontal pocket, fistula, mobility, and pain on percussion and mastication (Lertchirakarn et al., 2003). The dentin thickness (Chai \& Tamse, 2015; Awawdeh et al.), the external morphology of the root (Sathorn et al.) and the mesiodistal diameter (Katz et al.; Chai \& Tamse; PradeepKumar et al.; Awawdeh et al.) are characteristics which influence the distribution of mechanical forces throughout the tooth, (Lertchirakarn et al., 1999), often predisposing it to VRF (Sathorn et al.).

The morphology of the root canal systems of MFP have been investigated by various methods. At first, ex vivo methods were most frequently used, as they allowed the sample to be observed and handled directly, maintaining the original form of the root and canal (Awawdeh et al.; Matus \& Cantín, 2016). In clinical practice, conventional X-ray is the most common method of viewing the internal structures of the tooth. However it provides information in only two spatial planes, which often makes it difficult to diagnose the structure studied. Moreover, viewing may be hindered by superimposition of structures or by image distortion due to the sensitivity of the technique.

In recent decades, the use of Cone Beam Computed Tomography (CBCT) in endodontics has made it possible to view structures in vivo even when access is difficult, providing valuable information in three dimensions, without affecting the structure of the tooth or surrounding tissues. Today, CBCT is a complementary examination indicated both for diagnosis and for the planning of endodontic treatment. One of its main advantages is that it uses a lower dose of radiation than conventional computed tomography (Patel et al., 2009; Betancourt \& Fuentes, 2016).

Despite the high complexity of this tooth, and the fact that it is one of the teeth most frequently subjected to endodontic treatment, to date there are no morphological studies of the MFP in the Chilean population.

The aim of this in vivo study was to analyse by CBCT the radicular and canalicular morphology of MFP in a Chilean sub-population.

\section{MATERIAL AND METHOD}

The study was approved by the Scientific Ethics Committee (CEC) of Universidad de La Frontera (Protocol 034/18). We carried out a cross sectional, descriptive and observational in vivo study with CBCT examinations of 70 MFP, both left and right. The imaging examinations were provided by the Imaging Service of the Dentistry Faculty, Universidad de la Frontera, Temuco, Chile. The CBCT used had been requested as part of the examination, diagnosis and dental treatment planning of the respective patients between the months of November 2011 and December 2017. A Pax Zenith CBCT equipment from Vatech (Korea 2011) was used, with the following parameters: $90 \mathrm{kV}$ and $120 \mathrm{~mA}$; FOV 8 x 6 $\mathrm{cm}$, voxel size $0.12 \mathrm{~mm}$. No personal information was made available about the patients apart from their age and sex.

40 CBCT were included, belonging to subjects of both sexes, over 18 years of age, in which the presence of one or both MFP with complete root formation was observed. Examinations were excluded in which MFP were observed with endodontic filling or posts, rehabilitation with fixed prosthesis, calcification of canals, subjected to apical or root surgery, or with a mean angle greater than $30^{\circ}$.

The images were processed with Ez 3D 2009 software and projected on a LG LED screen, Model 42LE4300-SA. The images were analysed by 2 endodontists, with prior interobserver calibration. When no consensus could be reached, the decision was taken by a radiology specialist with experience in endodontics.

Observation used the following methodology: the MFP was located and a corono-apical exploration of the whole length of the root was carried out. To do this the transversal plane was rectified, orienting the sagittal and coronal sections in parallel, with respect to the long axis of the root. Sections of the image were obtained in the axial plane at intervals of $0.5 \mathrm{~mm}$ and a thickness of $1 \mathrm{~mm}$ for all the samples using multiplanar reformatting (MPR). Exploration followed the axial axis of each tooth to determine the number of roots and canals. Then the vertex of each root was located and tomography advanced to coronal in $2 \mathrm{~mm}$ sections, observing the surfaces at 2, 4 and $6 \mathrm{~mm}$ (apico-coronal exploration).

In each sample the number of roots and canals was observed, as well as the thickness of the cementodentinal walls around the root canals in the last $6 \mathrm{~mm}$ of the root. To calculate the latter parameter, a straight line was drawn from A (most concave point of the canal wall) to B (external surface of the root wall analysed) (Fig. 1). This procedure was repeated for each wall (buccal, palatine, mesial and distal) in each root surface analysed (Matus et al., 2017). 


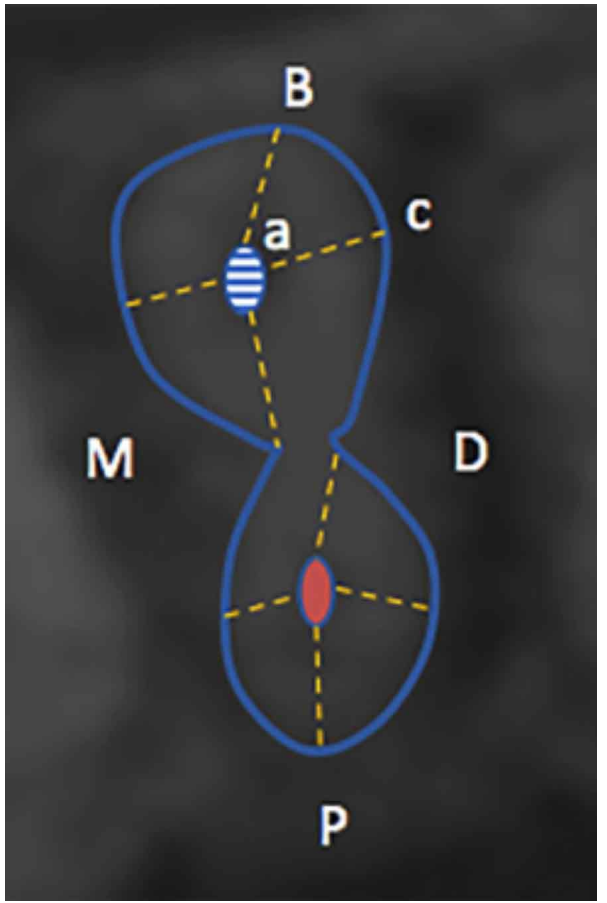

Fig. 1. CBCT methodology to measure the thickness of the cement-dentinal walls of the first maxillary premolars. a: most concave point of the corresponding canalicular wall c: outer surface of the root wall. The measurement was repeated for each of the walls (B: buccal, P: palatal, M: mesial and D: distal). In blue: buccal canal, in red: palatine canal.

Statistical analysis. The data were analysed by descriptive statistics (mean (M), standard deviation (SD), $95 \%$ confidence interval). Statistical analysis was carried out with the IBM SPSS software, version 23.0 (SPSS, Chicago, IL, USA). A value of $p>0.05$ was selected for the level of statistical significance, and one-factor ANOVA was used to relate the sections observed.

\section{RESULTS}

In $25 \%$ of the CBCT examinations analysed, one maxillary premolar was absent. Tooth 1.4 presented one root in $64.86 \%$ of cases (29.72\% males, $35.14 \%$ females) and two roots in $35.15 \%$ (24.32\% males, $10.83 \%$ females). Tooth 2.4 presented one root in $66.67 \%$ (36.36\% males, $30.31 \%$ females) and two roots in $33.33 \%$ (18.18\% males, $15.15 \%$ females). The frequency of one and two canals was observed to be $30 \%$ (21 teeth) and $70 \%$ (49 teeth) respectively. The mean length of the MFP was $20.9 \mathrm{~mm}$. The mean age of the patients studied was 30 years. In all the samples, the thinnest root walls were the proximal, mesial $1.11 \pm 0.55$ and distal $1.08 \pm 0.52$. The thickest dentinalwall was the palatine $(2.07 \pm 1.29)$, followed by the buccal (1.6 \pm 1.0$)$. The mean thicknesses of all the cementodentinal walls in the last $6 \mathrm{~mm}$ of the root (mean and standard deviation in $\mathrm{mm}$ ) are shown in Table I. No statistically significant differences were found in the thickness of the cementodentinal wall between males and females, nor in the location of the premolar in the maxilla (left or right side) $(\mathrm{p}>0.05)$.

\section{DISCUSSION}

A thorough knowledge of dental morphology is indispensable for successful endodontic treatment. Morphological study of the apical third of the root is of special interest due to the complex disposition of the root canals and the great variability found in the thickness of the cementodentinal walls (Degerness \& Bowles, 2010). So far as we know, this is the first approach to a CBCT study to determine variations in the apical morphology of MFP in a Chilean sub-population.

Different methods have been used to study the internal morphology of the root and the root canal system, including diaphanization (Kartal et al.), histological sections (Schwarze et al., 2002) and computed microtomography (De-Deus et al., 2019). These techniques have all provided valuable, accurate information, however they can only be applied after extraction of the tooth. CBCT is a conservative imaging technique, which gives a three-dimensional view of structures to which access is difficult. It is a complementary tool used for diagnosis and the planning of endodontic treatment, as it provides a view of the apical third of the root (mean and standard deviation in mm). BC: buccal canal; PC: palatine canal.

\begin{tabular}{lccc}
\hline \multirow{2}{*}{ Canal } & \multicolumn{3}{c}{ Section level from apex } \\
\cline { 2 - 4 } & $2 \mathrm{~mm}$ & $4 \mathrm{~mm}$ & $6 \mathrm{~mm}$ \\
\hline BC mesial & $0.90 \pm 0.55$ & $1.46 \pm 0.26$ & $1.73 \pm 0.32$ \\
BC distal & $0.88 \pm 0.54$ & $1.41 \pm 0.27$ & $1.62 \pm 0.28$ \\
BC buccal & $1.16 \pm 0.78$ & $1.96 \pm 0.54$ & $2.29 \pm 0.60$ \\
BC palatine & $1.45 \pm 1.11$ & $2.66 \pm 1.25$ & $3.73 \pm 1.52$ \\
PC mesial & $0.50 \pm 0.61$ & $0.84 \pm 0.75$ & $1.28 \pm 0.76$ \\
PC distal & $0.53 \pm 0.63$ & $0.83 \pm 0.72$ & $1.19 \pm 0.71$ \\
PC buccal & $0.90 \pm 1.28$ & $1.71 \pm 1.83$ & $1.58 \pm 0.99$ \\
PC palatine & $0.61 \pm 0.74$ & $0.96 \pm 0.85$ & $3.03 \pm 2.25$ \\
\hline
\end{tabular}


structure in all three planes: sagittal, coronal and axial. Its use has been found to increase the success rate of endodontic treatment (Patel et al., 2009). Two particular advantages are that it requires a smaller dose of radiation than conventional computerised tomography, and that it avoids the distortion and/or superimposition of structures that occur with conventional radiography. One limitation is that metallic restorations in the $\mathrm{CBCT}$ image zone may cause a radiographic artifact (Patel et al., 2019); for this reason, examinations containing amalgam, metal posts or metal crowns were excluded from this study.

The percentage distribution of the number of roots in each MFP in the present study was: one root, $65 \%$; two roots $35 \%$; the variation of a third root was $0 \%$. These percentages are consistent with findings reported in studies carried out in Chinese and Brazilian populations (Saber et al., 2019); however they differ from the results obtained by other authors in North America, the Far East and Turkey, who report incidence of between $30 \%$ and $60 \%$ for one root, between $41.7 \%$ and $70 \%$ for two roots and between $0 \%$ and $6 \%$ for three roots (Awawdeh et al.). Observations in a Spanish population using CBCT presented different results again, with a higher percentage of cases of 2 roots in first premolars (Abella et al., 2015). The differences in these results may be attributable to the sample size and to racial variations.

Turning to the number of canals, $78.5 \%$ of the teeth in our study presented two canals and $21.5 \%$ only one canal. These results are similar to those reported by Walter RT, who says that $87 \%$ of the MFP studied in a Chinese population presented two canals. The percentage of cases with two canals in our sample is within the range reported for patients of Caucasian origin, which is from $79 \%$ to 92 $\%$ (Walker, 1987).

The findings for the thickness of the cementodentinal walls showed that the proximal, mesial and distal walls were thinner than the buccal and palatine walls in all the sections. This intrinsic morphology of the MFP makes it one of the teeth most susceptible to vertical root fracture (Cohen et al.; PradeepKumar et al.). This is an important consideration when planning endodontic treatment, in order to avoid perforation or excessive weakening of the thinner walls (Lertchirakarn et al., 2003; Matus et al.); however, although the vestibular and palatine walls are thicker than the proximal, a high frequency of cases of VRF in the buccopalatine direction has been reported (Lertchirakarn et al., 1999, 2003). Lertchirakarn et al. (2003) observed that a diminution in the thickness of the proximal wall increases the concentration of stress in the buccal and palatine walls, and therefore their predisposition to fractures. These authors suggest that in response to excessive forces, the thinnest walls (proximal) are obliged to expand more rapidly that the thicker walls (buccal and palatine), and this asymmetric expansion creates additional tension on the internal surface, thus increasing the possibility of VRF in the bucco-palatine direction (Katz et al.). It must be borne in mind that due to its function and its position in the arch, the MFP is often subjected to high occlusal forces which act in different directions, increasing the likelihood of root fracture due to overload (PradeepKumar et al.).

This must be remembered during all stages of endodontic treatment, especially during chemicalmechanical preparation, since clinical practice may directly affect the resulting thickness of the dentinal walls. Instrumentation must be as conservative as possible, cleaning and shaping with abundant irrigation and seeking to give the canal a rounded form (Somma et al., 2009; Marchi et al., 2008; Matus et al.). Irregularities should be eliminated, leaving the walls smooth. This will reduce stress concentration and ensure that the forces are evenly distributed. Likewise the clinician must avoid excessive erosion of the dentinal walls by the use of ultrasound systems and/or the application of excessive forces during obturation (Oliveira et al., 2015; Chai \& Tamse; Matus et al.), especially in the thinner areas of the root.

\section{CONCLUSIONS}

The root morphology of the MFP is highly variable. The majority of MFP in a Chilean population presented one root with two root canals. In the apical area of the root, the thinnest walls were the mesial and distal. Care must be taken not to over-instrument the proximal walls to avoid perforations or fractures. CBCT has proved to be a useful diagnostic tool for in vivo study of dental morphology.

ACKNOWLEDGEMENTS. The authors are grateful for DIUFRO project DI18-0051- INI 2018. Study financed in part by the Research Directorate of Universidad de La Frontera.

MATUS, D.; FUENTES, R.; NAVARRO, P. \& BETANCOURT, P. Análisis morfológico de primeros premolares maxilares a través de tomografía computarizada de haz cónico en una subpoblación chilena. Int. J. Morphol., 38(5):1266-1270, 2020.

RESUMEN: El sistema de canal radicular del primer premolar maxilar (MFP) presenta una alta tasa de variación, especialmente a nivel apical. Esto complica la acción de las soluciones antisépticas y los instrumentos endodónticos a este nivel. El objetivo de este estudio in vivo fue analizar mediante tomografía 
computarizada de haz cónico (CBCT) la morfología radicular y canalicular de la MFP en una subpoblación chilena. Realizamos un estudio transversal, descriptivo y observacional in vivo con exámenes CBCT de 70 MFP, tanto a la izquierda como a la derecha. Los datos se analizaron mediante estadística descriptiva (media (M), desviación estándar (DE), con un intervalo de confianza del $95 \%$ ) y se utilizó ANOVA de un factor para relacionar las secciones observadas. El diente 1.4 presentó una raíz en el 64,86 $\%$ de los casos y dos raíces en el $35,15 \%$. El diente 2.4 presentó una raíz en el 66,67 \% de los casos y dos raíces en el 33,33 \%. Se observó que la frecuencia de uno y dos canales era del $30 \%$ y 70 $\%$, respectivamente. Las paredes con el espesor cementodentinal más pequeño fueron mesial $(1,11 \pm 0,55)$ y distal $(1,08 \pm 0,52)$. La pared dentinaria más gruesa fue la palatina $(2,07 \pm 1,29)$, seguida de la vestibular $(1,6 \pm 1,0)$. No se encontraron diferencias estadísticas entre machos y hembras en el grosor de la pared de la raíz, ni en la ubicación del premolar en el maxilar ( $p>0,05)$. En conclusión, la morfología de la raíz de la MFP es muy variable. Se debe tener cuidado de no sobre-instrumentar las paredes proximales para evitar perforaciones o fracturas. CBCT ha demostrado ser una herramienta de diagnóstico útil y efectiva para el estudio in vivo de la morfología dental.

PALABRAS CLAVE: Anatomía del canal radicular; Primer premolar maxilar; Fractura vertical de la raíz; Tomografía computarizada de haz cónico; Endodoncia

\section{REFERENCES}

Abarca, J.; Zaror, C.; Monardes, H.; Hermosilla, V.; Muñoz, C. \& Cantin, M. Morphology of the physiological apical foramen in maxillary and mandibular first molars. Int. J. Morphol., 32(2):671-7, 2014.

Abella, F.; Teixidó, L. M.; Patel, S.; Sosa, F.; Duran-Sindreu, F. \& Roig, M. Cone-beam computed tomography analysis of the root canal morphology of maxillary first and second premolars in a Spanish population. J. Endod., 41(8):1241-7, 2015.

Ahmad, I. A. \& Alenezi, M. A. Root and root canal morphology of maxillary first premolars: a literature review and clinical considerations. J. Endod., 42(6):861-72, 2016

Awawdeh, L.; Abdullah, H. \& Al-Qudah, A. Root form and canal morphology of jordanian maxillary first premolars. J. Endod., 34(8):956-61, 2008.

Betancourt, P. \& Fuentes, R. Cone beam computarized tomography analysis of a unusual mandibular canine with two independent roots and two canals. Biomed. Res. (India), 27(1):177-80, 2016.

Chai, H. \& Tamse, A. The effect of isthmus on vertical root fracture in endodontically treated teeth. J. Endod., 41(9):1515-9, 2015.

Cohen, S.; Berman, L. H.; Blanco, L.; Bakland, L. \& Kim, J. S. A demographic analysis of vertical root fractures. J. Endod., 32(12):1160-3, 2006.

De-Deus, G.; Rodrigues, E. A.; Belladonna, F. G.; Simões-Carvalho, M.; Cavalcante, D. M.; Oliveira, D. S.; Souza, E. M.; Giorgi, K. A.; Versiani, M. A.; Lopes, R. T.; et al. Anatomical danger zone reconsidered: a microCT study on dentine thickness in mandibular molars. Int. Endod. J., 52(10):1501-7, 2019.

Degerness, R. A. \& Bowles, W. R. Dimension, anatomy and morphology of the mesiobuccal root canal system in maxillary molars. J. Endod., 36(6):985-9, 2010

Kartal, N.; Ozçelik, B. \& Cimilli, H. Root canal morphology of maxillary premolars. J. Endod., 24(6):417-9, 1988.

Katz, A.; Wasenstein-Kohn, S.; Tamse, A. \& Zuckerman, O. Residual dentin thickness in bifurcated maxillary premolars after root canal and dowel space preparation. J. Endod., 32(3):202-5, 2006.
Lertchirakarn, V.; Palamara, J. E. \& Messer, H. H. Load and strain during condensation and vertical root fracture. J. Endod., 25(2):99-104, 1999.

Lertchirakarn, V.; Palamara, J. E. A. \& Messer, H. H. Patterns of vertical root fracture: factors affecting stress distribution in the root canal. J. Endod., 29(8):523-8, 2003

Li, J.; Li, L. \& Pan, Y. Anatomic study of the buccal root with furcation groove and associated root canal shape in maxillary first premolars by using microcomputed tomography. J. Endod., 39(2):256-8, 2013.

Marchi, G. M.; Mitsui, F. H. O. \& Cavalcanti, A. N. Effect of remaining dentine structure and thermal-mechanical aging on the fracture resistance of bovine roots with different post and core systems. Int. Endod. J., 41(11):969-76, 2008.

Matus, D. \& Cantín, M. Evaluation of isthmus frequency, location, and types in mesiobuccal roots of first maxillary molars. an ex vivo study. Int. J. Morphol., 34(2):804-10, 2016.

Matus, D.; Cantin, M.; Navarro, P. \& Fonseca, G. M. Evaluation of the cement/ dentin thickness of the mesiobuccal root of maxillary first molars by optical microscopy in a Chilean sample. Biomed. Res. (India), 28(16):6975-9, 2017.

Oliveira, M. A. V. C.; Venâncio, J. F.; Raposo, L. H. A.; Barbosa Júnior, N. \& Biffi, J. C. G. Morphometric evaluation and planning of anticurvature filing in roots of maxillary and mandibular molars. Braz. Oral Res., 29(1):1-9, 2015.

Patel, S.; Brown, J.; Pimentel, T.; Kelly, R. D.; Abella, F. \& Durack, C. Cone beam computed tomography in endodontics - A review of the literature. Int. Endod. J., 5(8):1138-52, 2019.

Patel, S.; Dawood, A.; Whaites, E.\& Pitt Ford, T. New dimensions in endodontic imaging: Part 1. Conventional and alternative radiographic systems. Int. Endod. J., 42(6):477-62, 2009.

Pécora, J. D.; Saquy, P. C.; Sousa Neto, M. D. \& Woelfel, J. B. Root form and canal anatomy of maxillary first premolars. Braz. Dent. J., 2(2):87-94,1992.

PradeepKumar, A. R.; Shemesh, H.; Jothilatha, S.; Vijayabharathi, R.; Jayalakshmi, S. \& Kishen, A. Diagnosis of vertical root fractures in restored endodontically treated teeth: A time-dependent retrospective cohort study. J. Endod., 42(8):1175-80, 2016.

Saber, S. E. D. M.; Ahmed, M. H. M.; Obeid, M. \& Ahmed, H. M. A. Root and canal morphology of maxillary premolar teeth in an Egyptian subpopulation using two classification systems: A cone beam computed tomography study. Int. Endod. J., 52(3):267-78, 2019.

Sathorn, C.; Palamara, J. E. A.; Palamara, D. \& Messer, H. H. Effect of root canal size and external root surface morphology on fracture susceptibility and pattern: A finite element analysis. J. Endod., 31(4):288-92, 2005.

Walker, R. T. Root form and canal anatomy of maxillary first premolars in a southern Chinese population. Endod. Dent. Traumatol., 3(3):130-4, 1987.

Wayman, B. E.; Patten, J. A. \& Dazey, S. E. Relative frequency of teeth needing endodontic treatment in 3350 consecutive endodontic patients. J. Endod., 20(8):399-401,1994.

\section{Corresponding author:}

Dr. Pablo Betancourt Henríquez

Centro de Investigación en Ciencias Odontológicas (CICO)

Facultad de Odontología

Universidad de La Frontera

Pabellón L, Campus Andrés Bello

Av. Francisco Salazar 01145

Temuco - CHILE

Email: pablo.betancourt@ufrontera.cl

Recibido : 09-01-2020

Aceptado : 14-01-2020 